\title{
Marine Diesel Engine Control to meet Emission Requirements and Maintain Maneuverability
}

Nielsen, Kræn Vodder; Blanke, Mogens; Eriksson, Lars; Vejlgaard-Laursen, Morten

Published in:

Control Engineering Practice

Link to article, DOI:

10.1016/j.conengprac.2018.03.012

Publication date:

2018

Document Version

Peer reviewed version

Link back to DTU Orbit

Citation (APA):

Nielsen, K. V., Blanke, M., Eriksson, L., \& Vejlgaard-Laursen, M. (2018). Marine Diesel Engine Control to meet Emission Requirements and Maintain Maneuverability. Control Engineering Practice, 76, 12-21.

https://doi.org/10.1016/j.conengprac.2018.03.012

\section{General rights}

Copyright and moral rights for the publications made accessible in the public portal are retained by the authors and/or other copyright owners and it is a condition of accessing publications that users recognise and abide by the legal requirements associated with these rights.

- Users may download and print one copy of any publication from the public portal for the purpose of private study or research.

- You may not further distribute the material or use it for any profit-making activity or commercial gain

- You may freely distribute the URL identifying the publication in the public portal 


\title{
Marine Diesel Engine Control to meet Emission Requirements and Maintain Maneuverability
}

\author{
Kræn Vodder Nielsen ${ }^{\mathrm{a}, \mathrm{b}}$, Mogens Blanke $^{\mathrm{b}, \mathrm{c}}$, Lars Eriksson ${ }^{\mathrm{d}}$, Morten Vejlgaard-Laursen ${ }^{\mathrm{a}}$ \\ ${ }^{a}$ MAN Diesel \& Turbo, Teglholmsgade 41, Copenhagen, Denmark \\ ${ }^{b}$ Automation and Control Group, Dept. of Electrical Engineering, Technical University of Denmark, Kgs. Lyngby, Denmark \\ ${ }^{c}$ AMOS CoE, Institute of Technical Cybernetics, Norwegian University of Science and Technology, Trondheim, Norway \\ ${ }^{d}$ Vehicular Systems, Department of Electrical Engineering, Linköping University, Linköping, Sweden
}

\begin{abstract}
International shipping has been reported to account for $13 \%$ of global $\mathrm{NO}_{x}$ emissions and $2.1 \%$ of global green house gas emissions. Recent restrictions of $\mathrm{NO}_{x}$ emissions from marine vessels have led to the development of exhaust gas recirculation (EGR) for large two-stroke diesel engines. Meanwhile, the same engines have been downsized and derated to optimize fuel efficiency. The smaller engines reduce the possible vessel acceleration, and to counteract this, the engine controller must be improved to fully utilize the physical potential of the engine. A fuel index limiter based on air/fuel ratio was recently developed [1], but as it does not account for EGR, accelerations lead to excessive exhaust smoke formation which could damage the engine when recirculated.

This paper presents two methods for extending a fuel index limiter function to EGR engines. The methods are validated through simulations with a mean-value engine model and on a vessel operating at sea. Validation tests compare combinations of the two index limiter methods, using either traditional PI control for the EGR loop or the recently developed fast adaptive feedforward EGR control [2]. The experiments show that the extended limiters reduce exhaust smoke formation during acceleration to a minimum, and that the suggested limiter, combined with adaptive feedforward EGR control, is able to maintain full engine acceleration capability. Sea tests with engine speed steps from 35 to 50 RPM, made peak exhaust opacity increase by only 5 percentage points when using the proposed limiter, whereas it increased 70 percentage points without the limiter.
\end{abstract}

Keywords: Exhaust gas recirculation, marine diesel engine, vessel maneuverability, emissions reduction, engine control

\section{Introduction}

Nitrogen oxide $\left(\mathrm{NO}_{x}\right)$ emissions from combustion engines harm the environment and human health because these emissions contribute to the formation of smog, acid rain and tropospheric ozone. International shipping accounts for approximately $13 \%$ of global NOx emission[3]. Increasingly strict emission limits have been adopted by the United Nations agency International Maritime Organization (IMO), which have thus far culminated in the Tier III standard [4]. This standard restricts $\mathrm{NO}_{x}$ emissions from slow-speed two-stroke crosshead diesel engines to 3.4 $\mathrm{g} / \mathrm{kWh}$. This emissions limit corresponds to a four-fold reduction compared to the earlier Tier II standard. This restriction applies to vessels constructed after the 1st of January 2016 when entering designated $\mathrm{NO}_{x}$ emission control areas (NECAs). Currently (2018), the US and Canadian coasts, Puerto Rico and the US Virgin Islands are NECAs. The North and Baltic Seas will be established as

Email addresses: kraenv.busk@man.eu (Kræn Vodder Nielsen), mb@elektro.dtu.dk (Mogens Blanke), larer@isy.liu.se (Lars Eriksson)
NECAs beginning in 2021. This factor of four reduction in emissions requires new approaches to engine design. Several methods, such as EGR, SCR (Selective Catalytic Reduction) and Dual Fuel Engines, are being developed and introduced to the market in order to comply to the new restrictions $[5,6,7,8,9]$. This paper focuses on the control of large two-stroke diesel engines with high-pressure EGR.

The main source of $\mathrm{NO}_{x}$ from a large two-stroke diesel engine is thermal $\mathrm{NO}_{x}$, which is formed during combustion where high peak temperatures lead to thermal formation of $\mathrm{NO}_{x}$, e.g. modeled using the Zeldovich mechanism[10]. An EGR system reduces the peak combustion temperature by recirculating exhaust gas to increase heat capacity and decrease oxygen availability in the combustion chamber. Figure 1 shows the components of the main gas flow in a diesel engine with high-pressure EGR developed by MAN Diesel \& Turbo. Intake air is compressed and cooled prior to entering the cylinder. Part of the hot exhaust gas is cleaned and cooled by the EGR unit, pressurized by the EGR blower and reintroduced to the scavenge receiver. The remaining part drives the turbocharger (TC). The EGR blower speed is controlled by an EGR control system that seeks to reach a load-dependent setpoint for the 
xygen fraction in the scavenge receiver [11]

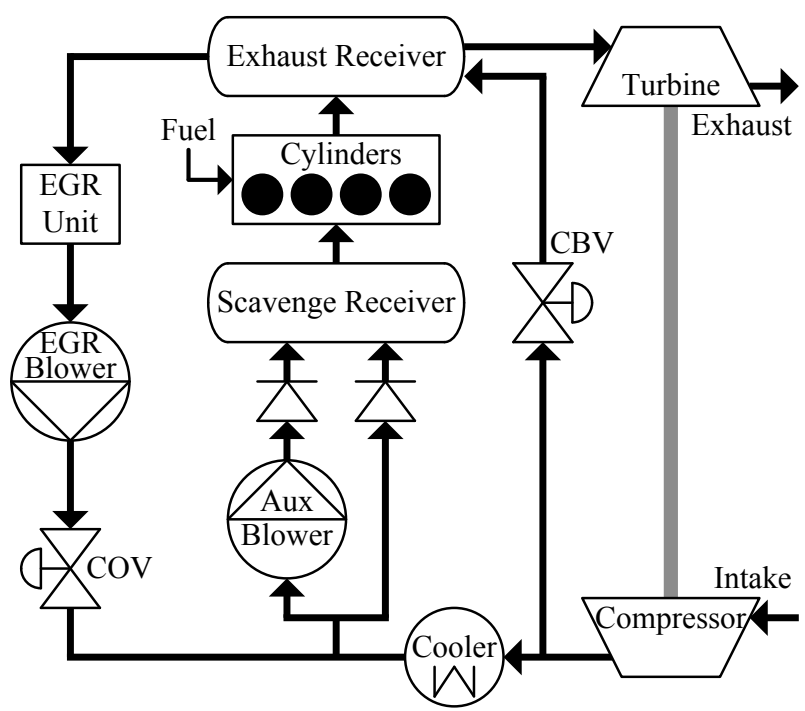

Figure 1: Overview of main gas flows and components of a large two-stroke diesel engine with high-pressure exhaust gas recirculation and cylinder by-pass valve.

In addition to reducing emissions, increased awareness of fuel efficiency has led to downsizing and derating of large two-stroke engines. International shipping has been reported to account for approximately $2.1 \%$ of global green house gas emissions [3]. The smaller engines are efficient in steady-state scenarios, but the decreased power availability makes the vessels less maneuverable. At low loads the engine performance is limited by the "turbo-lag" phenomenon, in which an increase in exhaust energy due to increased fuel input must accelerate the TC before more oxygen becomes available in the combustion chamber to react with a larger amount of fuel. An excess of fuel leads to the formation of black smoke, which pollutes the environment, is damaging to the engine, is waste of fuel and is prohibited by legislative authorities. The fuel index indicates the amount of fuel injected per combustion event. Traditionally, overfueling is avoided by implementing a fuel index limiter in the governor based on a fixed function of scavenge pressure. Basing the limit solely on the scavenge pressure tends to result in a conservative estimate that results in suboptimal acceleration. A recently developed fuel index limiter was based on a more advanced estimate of the air/fuel ratio [1].

Recirculation of exhaust gases decreases the oxygen fraction in the scavenge air. Therefore, the standard fuel index limiters based on either scavenge pressure or air/fuel ratio do not apply to this configuration. Using such limiters during large accelerations leads to excessive smoke formation since some oxygen in the scavenge flow is replaced by burned gases. In early EGR engines with slow EGR controllers, the scavenge oxygen level would actually decrease during acceleration, but recent developments of fast controllers have solved this issue[2]. Nevertheless, even with the fastest EGR controller, there is still a limit to how fast more fuel can be burned due to the TC dynamics. In this paper, the limit is calculated based on the oxygen/fuel ratio in order to maximize maneuverability while guaranteeing smoke-free acceleration. An intuitively easy solution to the acceleration problem is to simply switch off the EGR system during maneuvering, as the Tier III requirements apply to steady state conditions. However, the control system is expected to control the EGR system with a minimum of manual intervention. It is up to the EGR controller to reduce the EGR flow during acceleration and up to the index limiter to avoid excess fuel injection.

\subsection{Literature}

Combustion engine processes and modeling are extensively treated in $[10,12,13]$. The literature on the control of large two-stroke engines primarily addresses engine speed controllers (governors), as reported in $[14,15,16,17$, 18]. Modeling of the engine speed in response to fuel index showed that the TC inertia had a significant effect on the engine speed dynamics[19, 20, 21]. The first $\mathrm{NO}_{x}$ emission limits led to the use of variable geometry turbochargers, which required better control schemes to avoid smoke generation during loading transients [22]. New methods of injection timing has also been shown to decrease the formation of $\mathrm{NO}_{x}$ [23]. Mean-value modeling of a modern twostroke engine without EGR was reported by [24] and this model was used for several investigations in [25, 26, 27, 28]. A combustion model that showed the $\mathrm{NO}_{x}$ reduction potential of EGR was published in [29].

Fuel index limiters have not received considerable attention in the literature. The subject was briefly mentioned in [18]. A new air/fuel ratio limiter was presented in [30] and [1].

A number of papers on the control of EGR on large two-stroke engines have been published, starting with [31], where a mean-value engine model (MVEM) of a large two-stroke engine with high-pressure EGR was developed. Achievable EGR control performance with SISO design was investigated in [32] based on a linearization of the MVEM. An extended and improved version of the model was reported in [33] where the parameterization method was also revised. The authors of the present paper first proposed a simplified scavenge oxygen model and nonlinear adaptive EGR controller in [34]. A control-oriented scavenge oxygen model was analytically derived from the MVEM in [11], and a joint state and parameter estimator for this model was presented in [35] along with a proof of exponential convergence. An adaptive feedforward EGR controller based on an inversion of the control-oriented oxygen model was presented in [2] along with convergence proofs and results from a sea trial that showed significant improvement compared to a PI controller.

EGR control for four-stroke automotive engines is more common in the literature $[36,37,38,39,40,41,42]$ compared to marine two-stroke engines. These approaches 
cannot be directly transferred due to the differences in engine airflow setup and scavenging in 2-stroke and 4-stroke engines, system time constants, sensor setup, control objective and engine test bed availability $[29,18]$.

\subsection{Contributions}

The main contributions of this paper are as follows:

1. Two methods are proposed that extend an existing fuel index limiter to engines with EGR systems.

2 . The methods are validated in simulation with a highfidelity mean-value engine model and on a vessel operating at sea. Several combinations of limiters and EGR controllers are compared.

The engine control system proposed herein retains full vessel maneuverability, without leading to smoke formation, on prime mover diesel engines with EGR. This enables the application of EGR on downsized engines that enhance fuel efficiency while complying with the new Tier III $\mathrm{NO}_{x}$ emission restrictions [43]

\subsection{Outline of this paper}

Section 2 introduces the traditional and recent versions of fuel index limiters and explains why they do not apply to engines with exhaust gas recirculation. Section 3 briefly summarizes the dynamical models of the engine and EGR system that are used for simulation and for control design. Section 4 presents the two novel methods of how the air/fuel limiter can be extended to apply to engines with EGR. Both methods are validated through simulations and a sea trial in Section 5. Appendix A includes lists of abbreviations, symbols and subscripts used in the paper.

\section{Speed Governor with Fuel Index Limiters}

The purpose of a diesel engine governor is to control the engine speed to a specified setpoint using feedback from a measurement of engine speed and actuation via the fuel index. This is similar to cruise control in an automobile. Governors have evolved from the fly-weight speed governor employed by James Watt for reciprocating steam engines to complex mechanical governors with both proportional, integral and derivative control functions and finally to the modern electronic governors, where even more advanced control methods are implemented in software. The basic function is still a feedback controller designed from knowledge of the dynamic behavior from fuel index to engine speed near steady state.

During load transients, the engine can reach unwanted combinations of states and input that the main feedback design does not take into account. Artificial actuator saturation is therefore usually implemented in the governor software. This is referred to as a fuel index limiter. The setup is shown in Figure 2.

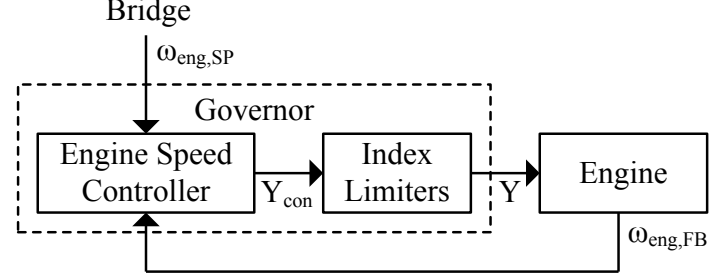

Figure 2: An engine speed setpoint is set by the bridge. The index limiters ensure that the output from the engine speed controller does not make the engine reach unwanted regions of operation (to limit, e.g., smoke formation and shaft stress).

The envelope of engine speed and produced power is restricted by such a limiter. The shafting system's specified bearing strength is exceeded if engine power is increased too fast compared to shaft speed. Therefore, a torquebased limiter is applied to the fuel index in present designs. This limiter is particularly restrictive at high loads where power and torque are high.

At low loads, the shaft torques are lower, and the critical quantity becomes oxygen available for combustion. Part of the energy released from the fuel during combustion drives the turbocharger. If the fuel index is increased too fast compared to the resulting increase in turbocharger speed (and thus the scavenge/boost pressure), then there is not sufficient oxygen for the complete combustion of fuel. This situation is traditionally avoided by applying a separate fuel index limit based on scavenge pressure (scavenge pressure limiter). However, although the amount of trapped air is related to the scavenge pressure, it is also affected by exhaust valve timing, which changes dynamically during transients. The scavenge pressure limiter gets little to no tuning for the specific engine. It therefore ends up being conservative, and acceleration performance from low loads is suboptimal.

The IMO's introduction of restrictions on the energy efficiency design index (EEDI)[43] has led to downsizing and derating of ship engines to optimize fuel efficiency [1]. Consequently, this has decreased the acceleration capability of affected ships. To compensate, MAN Diesel \& Turbo introduced a software upgrade to their engine controllers referred to as Dynamic Limiter Function (DLF) [1]. The purpose of this upgrade was to allow the engine controller to optimize specifically for acceleration when needed. This is achieved by changing the exhaust valve timing and by replacing the scavenge pressure limiter with a more precise fuel index limiter based on the trapped air mass in the combustion chamber.

A fuel index limiter based on trapped air mass can be derived by specifying a limit to the air/fuel ratio $\left(\lambda_{A}\right)$ of the combustion process, which is defined as

$$
\lambda_{A}=\frac{m_{\text {trap }}}{m_{f}}=\frac{m_{\text {trap }}}{m_{f, M C R} \cdot Y},
$$

where $m_{\text {trap }}$ denotes the mass of gas trapped in the cylin- 
der and $m_{f}$ is the mass of injected fuel. The latter is proportional to fuel index $Y$ with the proportionality constant being the mass of fuel trapped at maximum continuous rating $\left(m_{f, M C R}\right)$. If the limit of the air/fuel ratio is denoted as $\lambda_{L A}$, the limit to the fuel index (1) is

$$
Y_{L A}=\frac{m_{\text {trap }}}{m_{f, M C R} \cdot \lambda_{L A}} .
$$

DLF with the $\mathrm{Y}_{L A}$ limiter has been validated on a number of vessels. It allows for faster acceleration without smoke formation. However, the DLF does not apply to engines with EGR, because an underlying assumption of $\mathrm{Y}_{L A}$ in (2) is that the scavenge air has a constant oxygen fraction equal to that of ambient air. When EGR is applied the scavenge oxygen fraction is decreased from $21 \%$ to $16-18 \%$ and smoke formation can occur even though the $\frac{m_{\text {trap }}}{m_{f}}$ ratio is within the specified limit. Figure 3 shows an example.

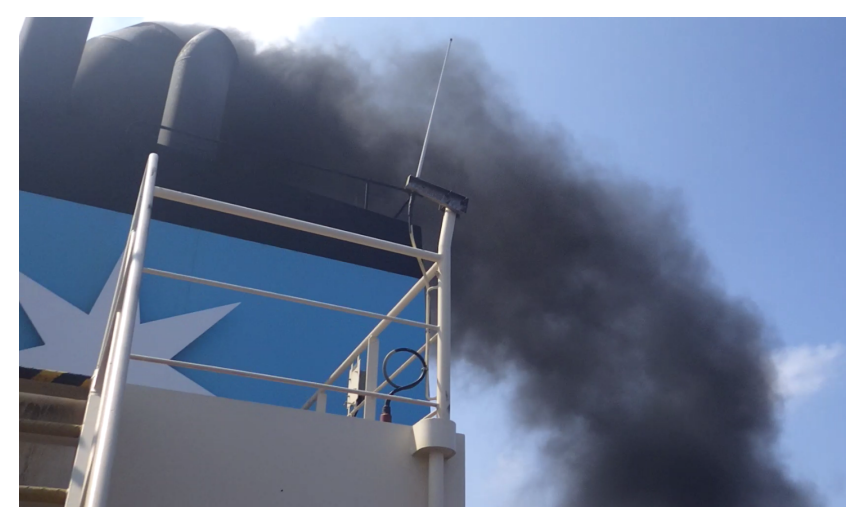

Figure 3: Exhaust smoke on a vessel with DLF and EGR during engine speed step. Thick black smoke is emitted for 45 seconds. In this test, the $Y_{L A}$ limiter was used in combination with PI EGR control.

Avoiding smoke formation under these conditions require further development of the fuel limiter. To arrive at refined types of fuel limiters, EGR system models are first revisited.

\section{EGR system models}

This section first presents the dynamic model used to simulate the effect of EGR on the gas composition and flows in a large two-stroke diesel engine. Second, a control oriented model of the molar scavenge oxygen fraction is presented. Finally, two generations of EGR controllers are introduced.

\subsection{Mean-Value Engine Model}

The dynamic simulation model used here was presented in [11]. It is a filling and emptying model with a meanvalue assumption for the flow through the cylinders. It represents the 4T50ME-X test engine located in MDT's Diesel Research Center in Copenhagen. An overview of the modeled components is presented in Figure 4. The model has four pressure states, a TC speed state and six states representing gas composition. This paper only uses the two oxygen fraction states rather than all six gas compositions.

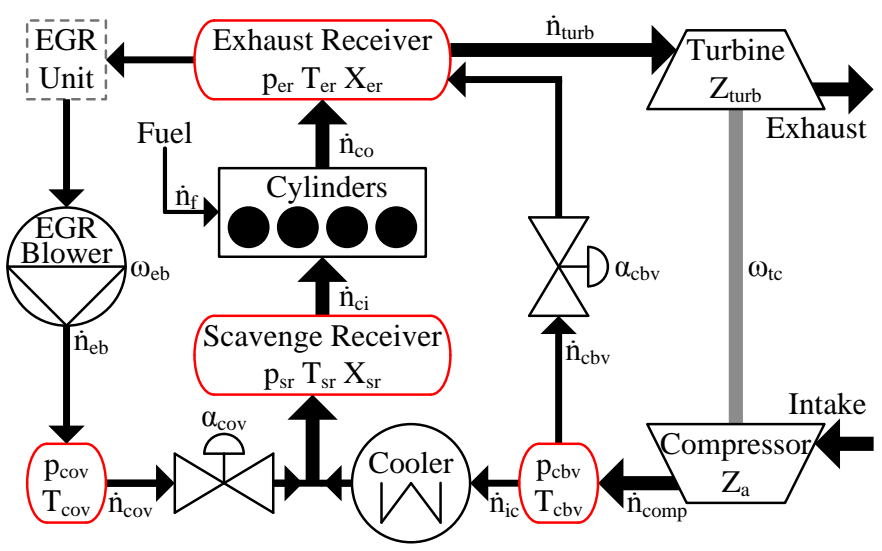

Figure 4: Overview of gas flows and components modeled in the MVEM.

Absolute pressures in the volumes, which are marked in red in Figure 4, are modeled isothermally as

$$
\dot{p}_{i}=\frac{R T_{i}}{V_{i}}\left(\dot{n}_{\text {in }}-\dot{n}_{\text {out }}\right),
$$

where $\dot{n}_{i}$ indicates molar gas flow. Turbocharger speed is modeled based on the turbine power $P_{\text {turb }}$, compressor power $P_{c o m p}$ and turbocharger moment of inertia $J_{t c}$

$$
\dot{\omega}_{t c}=\frac{P_{t u r b}-P_{c o m p}}{J_{t c} \omega_{t c}} .
$$

The molar gas composition fractions of the receivers are calculated based on the input flow and composition and the receiver pressure. The dynamic equation for the oxygen fractions in the volumes is

$$
\dot{O}_{i}=\frac{R T_{i}}{p_{i} V_{i}} \sum_{\text {input }=j} \dot{n}_{j}\left(O_{j}-O_{i}\right) .
$$

Gas that flows through the components between volumes are calculated from the input and output pressures of the component and in some cases an additional input $\epsilon_{i}$ are used (e.g. valve opening or turbocharger speed),

$$
\dot{n}_{i}=f\left(p_{\text {in }}, p_{\text {out }}, \epsilon_{i}\right) .
$$

In the cylinder component, the following lean combustion reaction is assumed

$$
\mathrm{CH}_{y}+\left(1+\frac{y}{4}\right) \mathrm{O}_{2} \rightarrow \mathrm{CO}_{2}+\frac{y}{2} \mathrm{H}_{2} \mathrm{O} .
$$

Here, the virtual fuel molecule $\mathrm{CH}_{y}$ is used, where $y$ is the average ratio of hydrogen atoms to carbon atoms in the fuel. From (7), the oxygen fraction of the flow exiting the cylinders is calculated as, 


$$
O_{c o}=\frac{\dot{n}_{c i} O_{s r}-\dot{n}_{f}\left(1+\frac{y}{4}\right)}{\dot{n}_{c i}+\frac{y}{4} \dot{n}_{f}} .
$$

The temperature of this flow was modeled in [33] using a modified limited-pressure diesel cycle.

A simple model of crankshaft speed is adapted from [20]. The dynamic equation is

$$
\dot{\omega}_{c}=\frac{P_{\text {ind }}-P_{\text {fric }}-P_{\text {prop }}}{J_{c} \omega_{c}},
$$

where $P_{\text {ind }}$ is indicated power, $P_{\text {fric }}$ is internal friction power, $P_{\text {prop }}$ is power delivered to the propeller and $J_{c}$ is the moment of inertia of the crankshaft-propeller system. To estimate the indicated power, the molar fuel flow $\dot{n}_{f}$ is calculated as being proportional to the product of engine speed and fuel index

$$
\dot{n}_{f}=k_{f} \omega_{c} Y .
$$

The indicated power is determined from the heat of combustion of fuel per unit mass $\left(k_{h c}\right)$ and thermal efficiency $\eta$

$$
P_{\text {ind }}=k_{h c} \dot{m}_{f} \eta=k_{h c} M_{f} k_{f} Y \omega_{c} \eta,
$$

where $M_{f}$ is the molar mass of the virtual fuel molecule $\mathrm{CH}_{y}$. Friction power is proportional to crankshaft speed

$$
P_{\text {fric }}=k_{\text {fric }} \omega_{c} .
$$

The power delivered to the fixed pitch propeller is modeled using a propeller curve and constant inflow to the propeller. Changes in ship speed are not included because the speed dynamics is slowly varying and will not affect the transient behaviours that relate to fuel limiters in the engine control. The power to shaft angular speed relation is hence,

$$
P_{\text {prop }}=k_{\text {prop }} \omega_{c}^{3} .
$$

The state vector of the full model is

$$
x=\left[\begin{array}{llllllll}
p_{s r} & p_{e r} & p_{c b v} & p_{c o v} & \omega_{t c} & \omega_{c} & O_{s r} & O_{e r}
\end{array}\right]^{T} .
$$

The inputs to the model are

$$
u=\left[\begin{array}{llll}
Y & \omega_{e b} & \alpha_{c o v} & \alpha_{c b v}
\end{array}\right]^{T} .
$$

The dynamic model is expressed in state space form as

$$
\dot{x}=f(x, u) .
$$

Hard accelerations that lead to smoke formation has been observed in the 5-50\% load range. At higher loads the acceleration is restricted by the torque limiter, as mentioned in Section 2. The MVEM model from [11] was designed for the $50-100 \%$ load range. The engine behavior was found to be similar throughout the total load range [44]. In this paper the model is used for validation of oxygen/fuel limiters by simulating a hard acceleration in the high load range, without the torque limiter.

\subsection{Control-Oriented Scavenge Oxygen Model}

The adaptive feedforward (AFF) EGR controller presented in [2] and one of the extensions presented in this paper are based on a control-oriented model $(\mathrm{COM})$ of the molar scavenge oxygen fraction that was presented in [11] and a nonlinear parameter estimator presented in [35]. The COM is a first-order Hammerstein model with three molar flows as inputs

$$
\tau \dot{O}_{s r}=-O_{s r}+g\left(\dot{n}_{f}, \dot{n}_{i c}, \dot{n}_{e g r}\right),
$$

where

$$
g\left(\dot{n}_{f}, \dot{n}_{i c}, \dot{n}_{e g r}\right)=O_{a}-\frac{\left(1+\frac{y}{4}\left(O_{a}+1\right)\right) \dot{n}_{f} \dot{n}_{e g r}}{\left(\dot{n}_{i c}+\frac{y}{4} \dot{n}_{f}\right)\left(\dot{n}_{i c}+\dot{n}_{e g r}\right)},
$$

which include two parameters: $O_{a}$ is the ambient oxygen fraction, and $y$ is the fuel constant also used in the MVEM. The flows are as shown in Figure 4. The fuel flow $\dot{n}_{f}$ is found from (10). The EGR flow $\dot{n}_{e g r} \approx \dot{n}_{e b}$ is calculated from the input and output pressures and blower speed using a blower map provided by the manufacturer of the EGR blower. The cooler flow is approximated based on the TC speed as

$$
\dot{n}_{i c}=\theta \cdot \beta\left(\omega_{t c}\right), \quad \beta\left(\omega_{t c}\right)=(1-\phi) \omega_{t c}+\phi \omega_{t c}^{2},
$$

where the parameter $\theta$ can be found using the nonlinear parameter estimator presented in [35]. The cooler flow is affected by other variables than TC speed (most notably the CBV opening). The approximation (19) is chosen because it is simple and captures the most significant changes in flow. The parameter estimator should then compensate for unmodelled effects and parameter uncertainties in (19), and [2] showed it to be capable of doing so. Changes in CBV opening have not been studied here but $\alpha_{c b v}$ could be added to the approximation if this should be necessary.

\subsection{EGR Controllers}

The extended limiters have to work in parallel with the EGR controller, and significant couplings between the two are expected. The goal of the EGR controller is to make the scavenge oxygen fraction reach a load-dependent setpoint by varying the EGR blower speed and the COV opening angle. Two generations of EGR controllers are used in this work. These controllers were compared in [2] without extensions to the index limiter. The first generation is the proportional-integral (PI) EGR controller that struggles during transients due to the slow process and sensors dynamics. The well-known simple structure of the controller is illustrated in Figure 5.

The second generation is the AFF EGR controller. The structure of this controller is shown in Figure 6. The AFF is based on an inversion of the input nonlinearity of the $\mathrm{COM}$ and a parameter estimator that ensures convergence of the measured scavenge oxygen error. Exponential convergence was proven in [2]. The AFF utilizes the known 


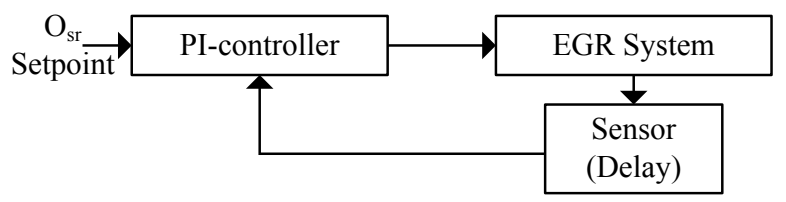

Figure 5: The PI EGR controller is a simple and well-known approach to regulate the scavenge oxygen fraction to its setpoint. The sensor and process dynamics make it vulnerable to engine load transients.

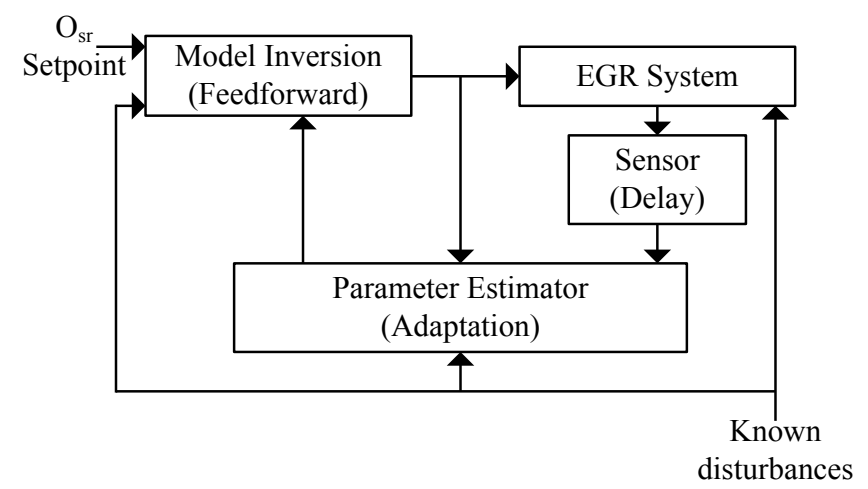

Figure 6: The adaptive feedforward EGR controller allows for rapid reactions to load changes. A parameter estimator ensures convergence of the controller error. fuel flow and turbocharger speed in the inverted model and therefore reacts rapidly to load transients.

Although it was shown in [2] that the AFF outperforms the PI in loading transients, the AFF also makes the control software more complex and less intuitive. If a combination of a PI EGR controller with a simple extension of the fuel index limiter is able to solve the smoke problem without degrading the acceleration, that might be the preferable solution.

\section{EGR Fuel Index Limiters}

The $Y_{L A}$ limiter does not apply to engines with EGR, because the assumption of a constant scavenge oxygen fraction is violated. This section presents two methods for extending the limiter to represent an oxygen/fuel limiter rather than an air/fuel limiter. The concept of an oxygen/fuel limiter is explained first.

\subsection{Oxygen fuel limiter}

On an engine without EGR, the limit to the air/fuel ratio ensures that sufficient oxygen is available for combustion of the fuel. Without EGR, the scavenge air has a constant oxygen fraction equal to that of the ambient air. Therefore, it does not matter whether the limit is specified as air/fuel or oxygen/fuel. With EGR, the scavenge oxygen fraction varies, and therefore, it is necessary to limit the oxygen/fuel ratio $\lambda_{O}$ rather than the air/fuel ratio $\lambda_{A}$. The oxygen/fuel ratio is defined as

$$
\lambda_{O}=\frac{m_{O, t r a p}}{m_{f}}=\frac{n_{O_{2}, \text { trap }} M_{O_{2}}}{m_{f, M C R} \cdot Y},
$$

where $m_{\mathrm{O}_{2} \text {,trap }}$ is the mass of oxygen trapped in the cylinder and $M_{\mathrm{O}_{2}}$ is the molar mass of $\mathrm{O}_{2}$. Using the molar scavenge oxygen fraction $O_{s r}$,

$$
\lambda_{O}=\frac{n_{t r a p} O_{s r} M_{O_{2}}}{m_{f, M C R} \cdot Y} .
$$

Converting back to the mass of trapped gas rather than moles, the air/fuel ratio from (1) appears in (21) as

$$
\lambda_{O}=\frac{m_{\text {trap }}}{m_{f, M C R} \cdot Y} \cdot \frac{O_{s r} M_{O_{2}}}{M_{\text {trap }}}=\lambda_{A} \frac{O_{s r} M_{O_{2}}}{M_{\text {trap }}} .
$$

The ratios hence scale with the scavenge oxygen fraction. The constant $\frac{M_{\mathrm{O}_{2}}}{M_{\text {trap }}}$ is needed to relate molar oxygen fraction to the mass-based ratio. The existing limiter $\lambda_{L A}$ is based on the assumption that the scavenge gas is ambient air $\left(O_{s r}=O_{a}\right)$. Equation (22) is used to calculate the oxygen/fuel ratio at this limit,

$$
\lambda_{L O}=\lambda_{L A} \frac{O_{a} M_{O_{2}}}{M_{\text {trap }}} .
$$

The result $\left(\lambda_{L O}\right)$ is used as oxygen/fuel ratio limit when running EGR. A fuel index limit based on the oxygen/fuel ratio limit is, from (22),

$$
Y_{L O}=\frac{m_{t r a p} O_{s r} M_{O_{2}}}{m_{f, M C R} \cdot \lambda_{L O} M_{t r a p}} .
$$

Inserting the result from (23),

$Y_{L O}=\frac{m_{\text {trap }} O_{s r} M_{O_{2}}}{m_{f, M C R} \cdot \lambda_{L A} \frac{O_{a} M_{O_{2}}}{M_{\text {trap }}} M_{\text {trap }}}=\frac{m_{\text {trap }}}{m_{f, M C R} \cdot \lambda_{L A}} \cdot \frac{O_{s r}}{O_{a}}$.

Extending $Y_{L A}$ to $Y_{L O}$ is obtained by combining (2) and (25),

$$
Y_{L O}=Y_{L A} \frac{O_{s r}}{O_{a}} .
$$

This result shows that the existing air/fuel ratio limiter $Y_{L A}$ (that assumes no EGR) can be converted to an oxygen/fuel ratio limiter $Y_{L O}$ by scaling with the instantaneous value of $\frac{O_{s r}}{O_{a}}$. This makes intuitive sense because $\frac{O_{s r}}{O_{a}}$ is the ratio of available oxygen compared to "no-EGR" conditions.

\section{2. $Y_{L O S}-$ Oxygen/fuel limiter based on $\mathrm{O}_{2}$ sensor}

A first method to extending the air/fuel limiter to be an oxygen/fuel ratio limiter is to use the output of the oxygen sensor mounted in the scavenge receiver

$$
Y_{L O S}=Y_{L A} \cdot \frac{O_{s r, s e n s}}{O_{a}}
$$


While simple and intuitive, this has two drawbacks. First, it relies on the scavenge oxygen sensor which is known to have a time delay of 10-20 seconds and a firstorder filtering effect with a time constant in the same range. The calculated limit will therefore be inaccurate, when the scavenge oxygen content changes during acceleration. Second, an increase in fuel index will lead to a decrease in the scavenge oxygen fraction, until the EGR controller has compensated by lowering the EGR rate. The $O_{s r}$ decrease negatively affects the index limiter. Thus, an unwanted feedback loop would be created from fuel index through scavenge oxygen back to fuel index. Combined with the sensor and process dynamics, such a loop could possibly lead to degradation of acceleration performance. In the worst case oscillations could occur in fuel index during acceleration, rather than the desired steady increase. This phenomenon is referred to as limiter loop oscillations (LLO) in the remainder of the text.

\section{3. $Y_{L O M}$ - Oxygen/fuel limiter based on $\mathrm{O}_{2}$ model}

With focus on handling the LLO issue explained above, a second method to extend the limiter is to use the COM model from Section 3.2 and the adaptive scavenge oxygen estimator [35] in (26). The dynamics of the COM with adaptive estimator mostly represents sensor dynamics, and as these can be disregarded, this approach leaves only the input nonlinearity $g\left(\dot{n}_{f}, \dot{n}_{i c}, \dot{n}_{e g r}\right)$ as a factor,

$$
Y_{L O M}=Y_{L A} \cdot \frac{g\left(\dot{n}_{f}, \dot{n}_{i c}, \dot{n}_{e g r}\right)}{O_{a}},
$$

where fuel flow $\dot{n}_{f}$ follows from measured fuel index and engine speed in (10), such that,

$$
Y_{L O M}=Y_{L A} \cdot \frac{g\left(k_{f} \cdot \omega_{e n g} \cdot Y, \dot{n}_{i c}, \dot{n}_{e g r}\right)}{O_{a}} .
$$

This relation represents a static version of the limiter loop because $Y$ is used to calculate the limit to itself. This can be solved by noting that $Y \leq Y_{L O M}$. Thus, on the limit, $Y=Y_{L O M}$, such that

$$
Y_{L O M}=Y_{L A} \cdot \frac{g\left(k_{f} \cdot \omega_{e n g} \cdot Y_{L O M}, \dot{n}_{i c}, \dot{n}_{e g r}\right)}{O_{a}} .
$$

Inserting the expression for $g()$ leads to a 2nd-order equation in $Y_{L O M}$

$$
\begin{aligned}
k_{f} \omega_{c}\left(\frac{y}{4}-\right. & \left.\frac{1+\frac{y}{4}\left(O_{a}+1\right)}{O_{a}} \cdot \frac{\dot{n}_{e g r}}{\dot{n}_{i c}+\dot{n}_{e g r}}\right) Y_{L O M} \\
& -\frac{\dot{n}_{i c}}{Y_{L A}} Y_{L O M}-\frac{\frac{y}{4} k_{f} \omega_{c}}{Y_{L A}} Y_{L O M}^{2}+\dot{n}_{i c}=0,
\end{aligned}
$$

where EGR flow $\dot{n}_{e g r}$ is found from the blower speed, upand downstream pressures and a blower map. Cooler gas flow $\dot{n}_{i c}$ is calculated with (19), where $\theta$ is the output of the parameter estimator from [35]

$$
\hat{\theta}=k\left(\tau O_{s r, \text { meas }}+\int O_{s r, \text { meas }}-g\left(\dot{n}_{f}, \dot{n}_{i c}(\hat{\theta}), \dot{n}_{\text {egr }}\right) \mathrm{dt}\right),
$$

where $k>0$ and the time constant of gas mixing and sensor dynamics is represented by $\tau$. The estimator error was proven to converge exponentially to a small region around zero in [35]. When the 3 flows are determined, (31) can be solved, and the positive solution is then used as a fuel index limiter.

The limiter $Y_{L O M}$ has the advantage that it is not directly influenced by the scavenge oxygen sensor delay, it is only indirectly influenced through the parameter estimator. The negative feedback loop from fuel index to scavenge oxygen and back to fuel index explained in Section 4.2 is handled by $Y_{L O M}$ by formulating the loop (without dynamics) as a $2^{\text {nd }}$ order equation and solving it. The solution represents the amount of fuel that can be burned taking into account the decrease of scavenge oxygen when increasing the fuel burning, assuming that the scavenge oxygen reaction is instantaneous. Thus the index limiter is initially conservative because it sets the limit so low that it will not have to decrease the limit during acceleration due to drop in $O_{s r}$. After the initial step of fuel index, this limiter tends to increase rapidly as it reacts instantaneously to changes in EGR and cooler flow.

Comparing the two suggested limiters, $Y_{L O M}$ is more complex than $Y_{L O S}$, and $Y_{L O M}$ ignores the process dynamics. However, $Y_{L O M}$ offers salient features over $Y_{L O S}$ as explained above.

\section{Results}

The two methods of limiter extension are first validated through simulations with the MVEM and then in acceleration tests on a vessel operating at sea. Combinations of the two methods are tested with both versions of EGR controllers. Figure 7 shows an overview of the governor, EGR controller and engine setup.

\subsection{Simulation}

The MVEM described in Section 3.1 is used for validation of the proposed limiters. The MVEM is implemented in MATLAB Simulink along with the two generations of EGR controllers: the slow PI controller and the fast adaptive feedforward controller (AFF). The air/fuel ratio is calculated internally in the MVEM and used with Equation (2) to provide $Y_{L A}$. Calculation of $Y_{L O S}$ and $Y_{L O M}$ is also implemented to test the limiters in closed loop. CBV opening is kept at $45 \%$ during the simulations.

The first scenario is a loading transient where the fuel index setpoint is changed from 60 to $100 \%$. The engine load (power) changes from 43 to $100 \%$ during the transient. The limiter extensions $Y_{L O S}$ and $Y_{L O M}$ are simulated in a closed loop one at a time, combined with the fast AFF EGR controller. The goal is to increase the fuel 


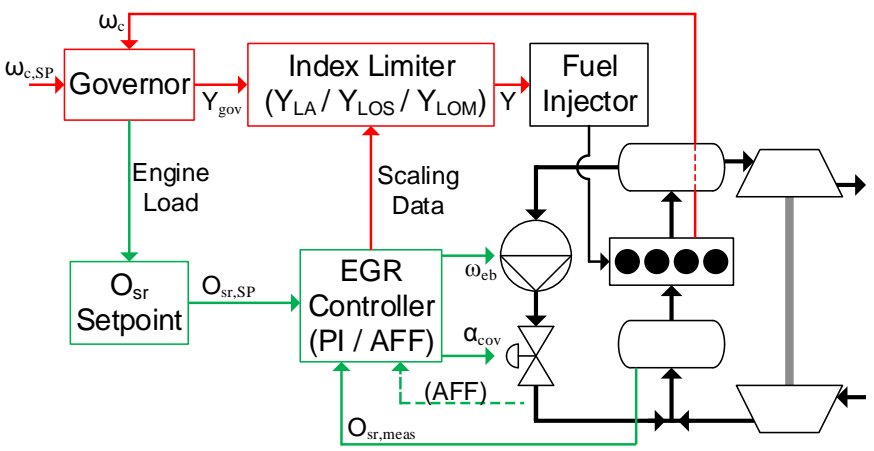

Figure 7: Overview of the governor (red) and EGR (green) control systems. The two systems control coupled variables of the same process and interact through the engine load signal and data for scaling of the index limiter. The dashed green line refers to TC speed, EGR flow and fuel flow data used by the AFF EGR controller. index limit (and thereby $\omega_{c}$ ) as fast as possible without exceeding the oxygen fuel equivalence ratio limit specified as 1.1. Figure 8 presents the result. $Y_{L O M}$ begins at a lower value than $\mathrm{Y}_{L O S}$ due to the solution of LLO, but the limits quickly converge during the transient, and no significant performance difference is observed. The AFF EGR controller is able to keep $O_{s r}$ almost constant in spite of the increased fuel flow. It effectively prevents LLO and issues with sensor delay. Both methods make the oxygen/fuel equivalence ratio saturate at 1.1 as desired.

The available MVEM only simulates the high-load region $(50-100 \%)$ because it was developed with focus on efficiency related simulations in the normal operational range. TC response is faster in the high power range than in the low-load region. Fast accelerations and subsequent smoke formation occur in this region, and slow TC response worsens the potential scavenge oxygen peaks, and therefore also the risk to encounter LLO phenomena. An MVEM with extended range would be desirable to better simulate the low-load region but MVEM development was not within the scope of this research. Instead, to simulate the worst case conditions for the limiters, the index setpoint step from 60 to $100 \%$ was simulated again, but with: TC moment of inertia tripled to slow the TC response; faster $\mathrm{O}_{2}$ sensor dynamics; slow PI EGR controller. The result is presented in Figure 9. $Y_{L O S}$ now shows a small "overshoot" for 20 seconds before converging with $Y_{L O M}$. The oxygen/fuel equivalence ratio exceeds its limit during this overshoot, whereas for $Y_{L O M}$, the behavior is slightly on the conservative side.

The conclusions of the simulations are that the limiter extensions perform similarly well in the simulation of a load transient in the high-load range with use of the AFF EGR controller. With slower turbocharger dynamics, faster sensor dynamics and combined with the PI EGR controller, the $Y_{L O S}$ limiter causes slight LLO and violates the oxygen/fuel limit.
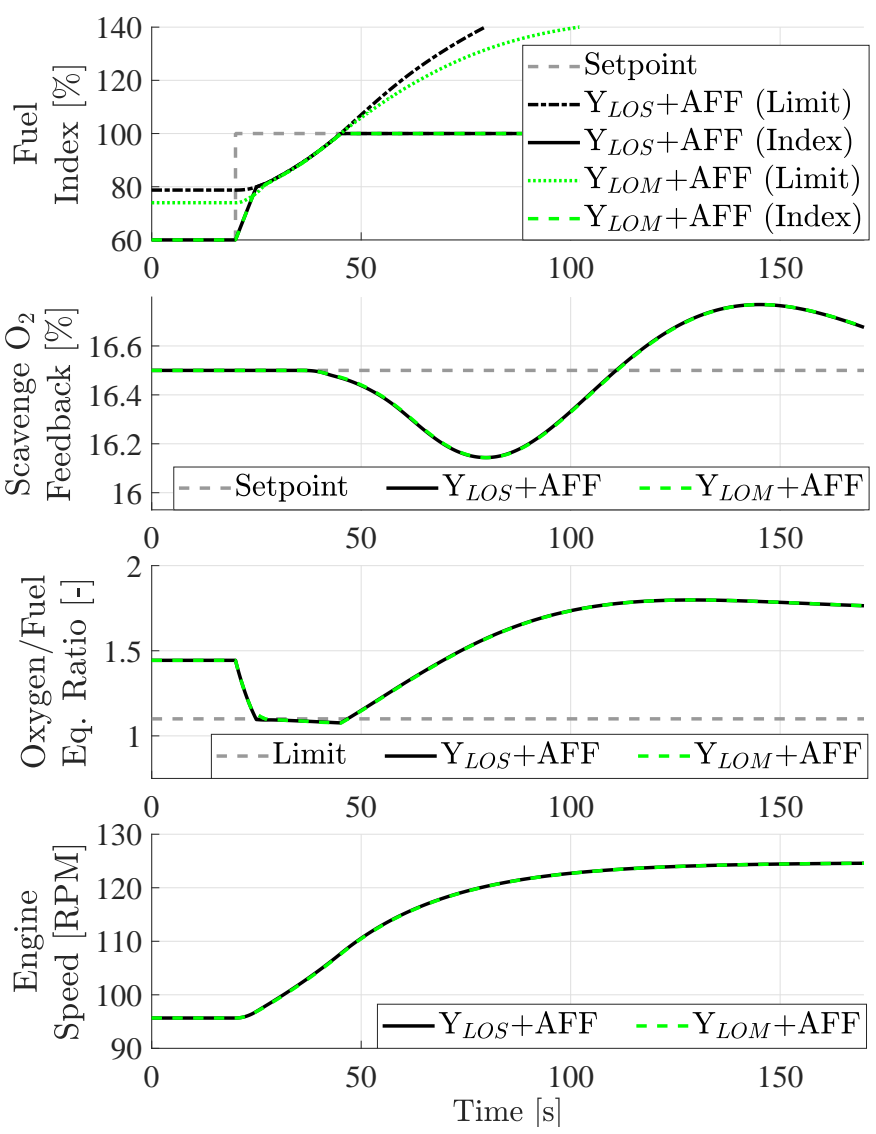

Figure 8: Closed loop simulations of MVEM with AFF EGR controller and either $Y_{L O S}$ or $Y_{L O M}$ during transient from 43 to $100 \%$ load. The limiters show similar performance, and both saturate the oxyen/fuel equivalence ratio at the limit of 1.1 .

\subsection{Experimental validation}

The limiters were experimentally validated on the container vessel Maersk Cardiff during operation in the South China Sea. A series of similar large engine speed setpoint steps where conducted in the maneuvering range with different combinations of index limiters and EGR controllers. The engine onboard this vessel does not have a cylinder bypass valve $(\mathrm{CBV})$.

$Y_{L O S}$ was tested with both PI and AFF, whereas $Y_{L O M}$ was only tested with AFF EGR control. Figure 10 presents the results. $Y_{L O S}+\mathrm{PI}$ clearly causes an amount of LLO to reduce engine acceleration. With $Y_{L O S}+\mathrm{AFF}$ the LLO is less significant and with $Y_{L O M}+\mathrm{AFF}$ it is completely avoided. The latter solution catches up to $Y_{L O S}+\mathrm{AFF}$ at approximately $45 \mathrm{RPM}$ and provides the fastest acceleration to 50 RPM among the tests.

An opacimeter mounted in the exhaust outlet allowed for comparison of smoke formation. Furthermore, the exhaust outlet was recorded with a video camera to provide visual validation. Figure 11 shows the engine speeds and opacity responses of 5 combinations of limiters and EGR control. Combining the AFF EGR control with an extended limiter clearly caused the least smoke formation, 

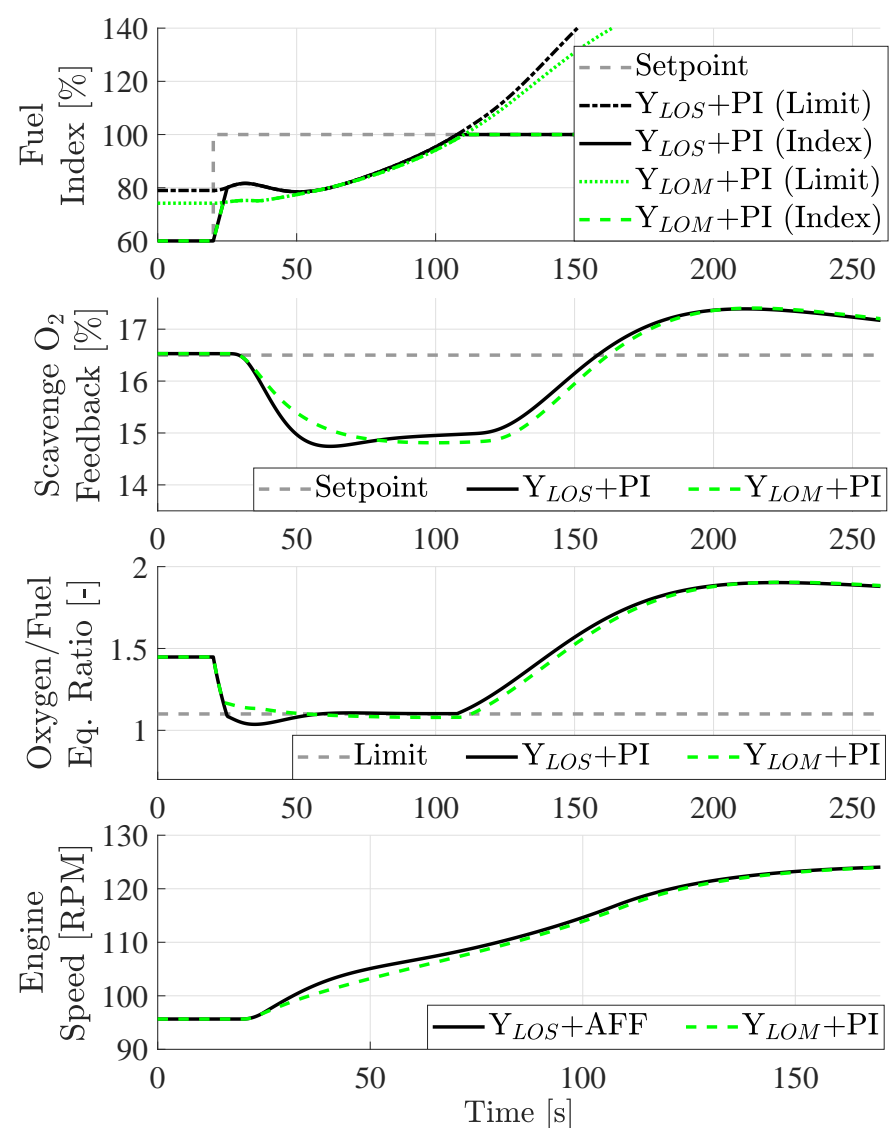

Figure 9: Closed loop simulations of MVEM with PI EGR controller and either $Y_{L O S}$ or $Y_{L O M}$ during transient from 43 to $100 \%$ load. For this simulation, the TC moment of inertia was tripled and $\mathrm{O}_{2}$ sensor dynamics were artificially fast to induce the worst case with respect to limiter oscillation. $Y_{L O S}$ causes slight LLO and violation of the oxygen/fuel limit. whereas the first approach with PI EGR control and no extension performs poorly. Figure 12 shows stills from the videos of the exhaust outlet during these steps. Clearly visible smoke formation occurs during steps with the nonextended $Y_{L A}$ limiter, whereas the extended limiters reduce the visible smoke to a minimum. Table 1 summarizes the conclusions from the experiments.

\section{Conclusions}

This paper presented two methods for extending a fuel index limiter based on air/fuel ratio to a limiter based on oxygen/fuel ratio for application to diesel engines with exhaust gas recirculation. The first method was based on a measurement of the scavenge oxygen fraction. The second method was based on a control oriented model $(\mathrm{COM})$ and a nonlinear estimator.

Closed loop simulations with a mean value engine model showed that the two methods performed similarly well in the high-load range when combined with fast adaptive feedforward (AFF) exhaust gas recirculation (EGR) control. In a simulation of the worst case conditions (with

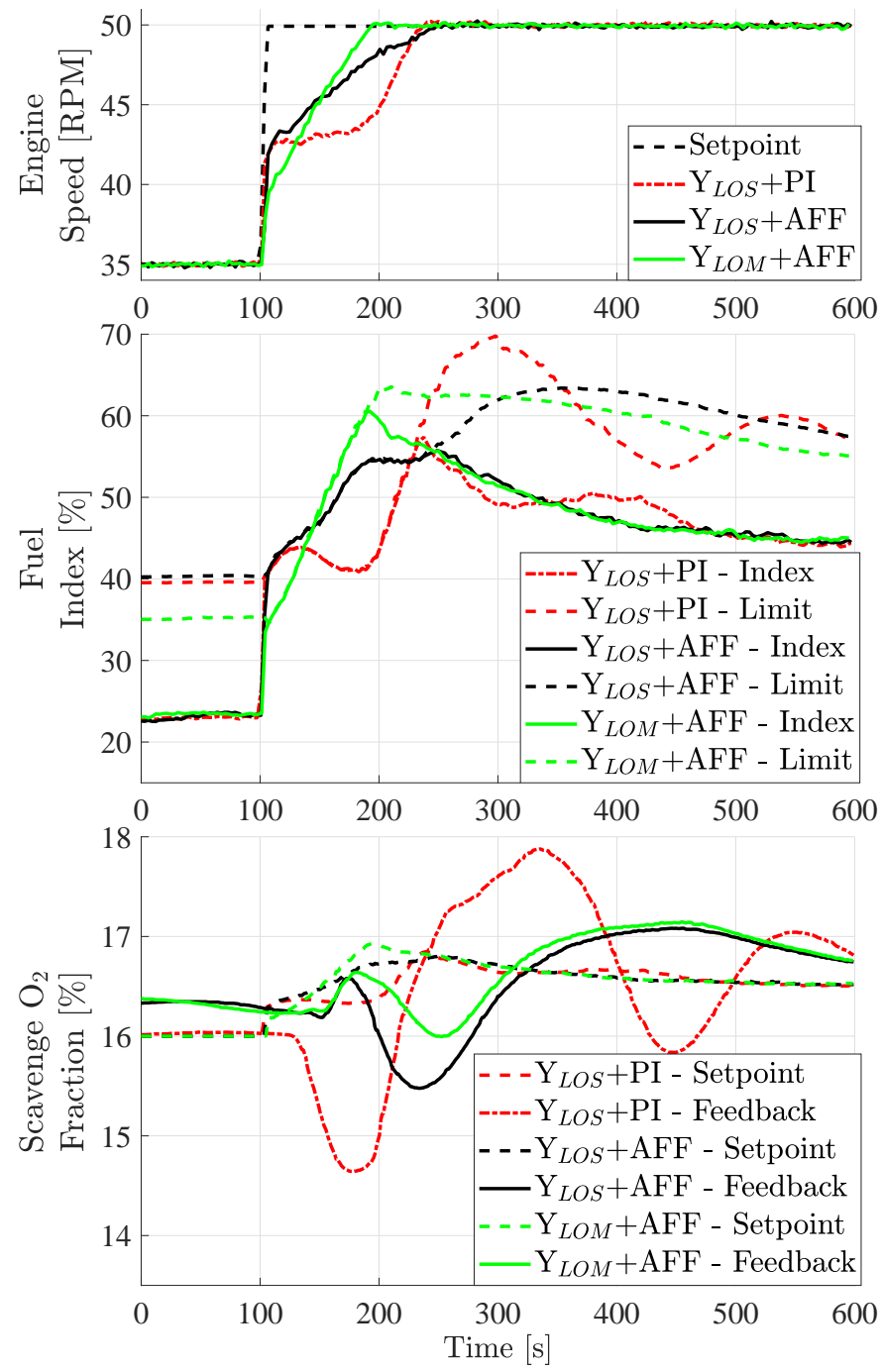

Figure 10: A comparison of 3 similar engine speed setpoint steps performed on the vessel Maersk Cardiff with different combinations of limiters and EGR controllers. The $Y_{L O M}$ combined with AFF EGR controller provides the fastest acceleration from 35 to 50 RPM.

slow model dynamics and a PI EGR controller), the extension with a limiter based on the oxygen sensor oscillated slightly. This was not the case with the AFF control.

Sea trial experiments showed very significant smoke reduction when using the proposed limiters. The best acceleration performance was achieved by combining the limiter extension based on the COM and the nonlinear estimator, with the adaptive feedforward EGR controller.

The advances described in this paper remove a significant practical obstacle for the EGR technology to reduce $\mathrm{NO}_{x}$ emissions from large diesel engines. The sophisticated engine control methods facilitate the application of EGR systems on downsized diesel engines for simultaneous maximization of fuel efficiency and minimization of $\mathrm{NO}_{x}$ emissions while maintaining optimal vessel maneuverability without damaging the engine. The limiters proposed here are currently being implemented in commer- 


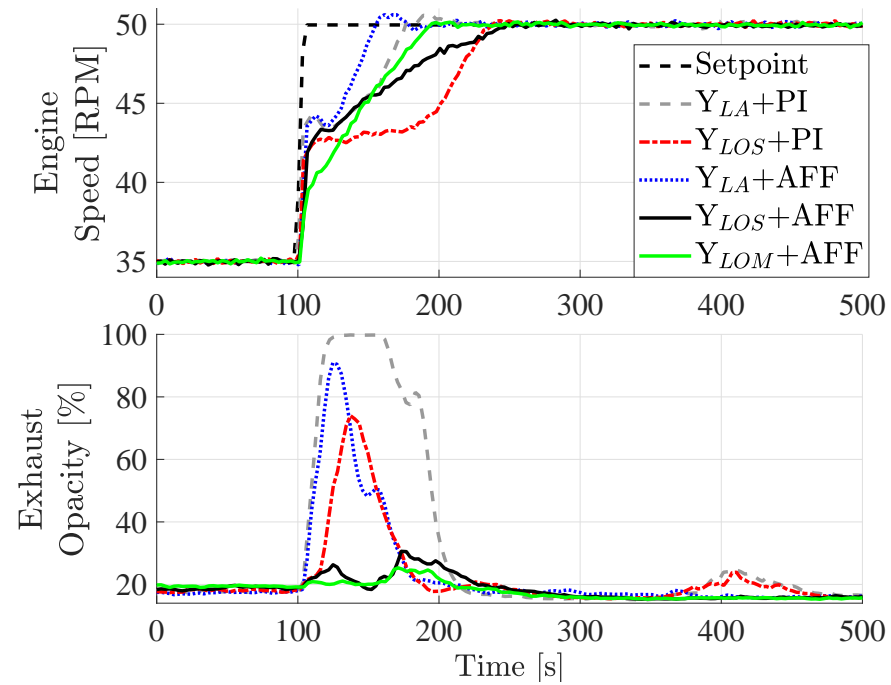

Figure 11: A comparison of engine speed and smoke for 5 similar engine speed setpoint steps performed on the vessel Maersk Cardiff with different combinations of limiters and EGR controllers. Acceleration performance slightly degrades when basing the limiter conversion on the oxygen sensor $\left(\mathrm{Y}_{L O S}\right)$.

Table 1: Conclusions from the experiments. The best performance is achieved by combining the $\mathrm{Y}_{L O M}$ limiter with AFF EGR control.

\begin{tabular}{l||c|c} 
& PI & AFF \\
\hline \hline $\mathrm{Y}_{L A}$ & Heavy smoke. & Reduced smoke. \\
& +80 pp exh opacity. & +70 pp exh opacity. \\
\hline $\mathrm{Y}_{L O S}$ & Slight smoke. & No smoke. \\
& +55 pp exh opacity. & +10 pp exh opacity. \\
& Reduced acceleration. & Good acceleration. \\
\hline $\mathrm{Y}_{\text {LOM }}$ & Not tested. & No smoke. \\
& & $+\mathbf{5}$ pp exh opacity. \\
& & Best acceleration.
\end{tabular}

cially available EGR control software along with the adaptive feedforward EGR controller. The effects of varying the cylinder bypass valve (CBV) opening has yet to be studied in order to support engines with CBV.

\section{Acknowledgments}

This work was partially funded by the Danish Agency for Science, Technology and Innovation, grant number 135500071B.

We thank MAN Diesel \& Turbo and Maersk Line for supporting the experiments on the vessel Maersk Cardiff.

\section{References}

[1] M. D. . Turbo, The dynamic limiter function, Technical Paper (2016).

URL http://marine.man.eu/two-stroke/technical-papers

[2] K. Nielsen, M. Blanke, L. Eriksson, M. Vejlgaard-Laursen, Adaptive feedforward control of exhaust recirculation in large diesel engines, Control Engineering Practice 65 (2017) 26-35. doi:10.1016/j.conengprac.2017.05.003.

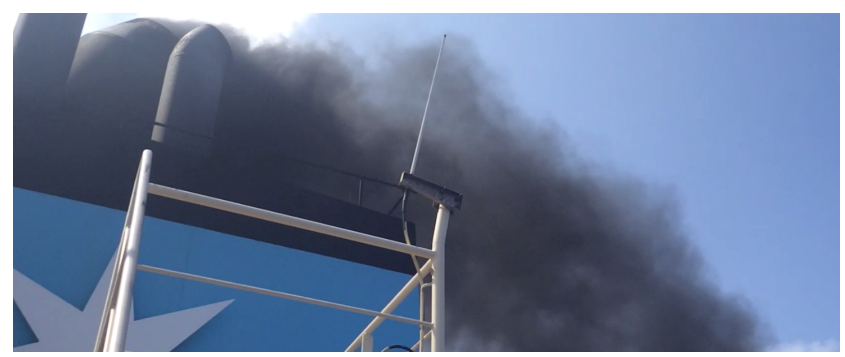

(a) $\mathrm{Y}_{L A}+\mathrm{PI}$. Thick black smoke is emitted for 45 seconds.

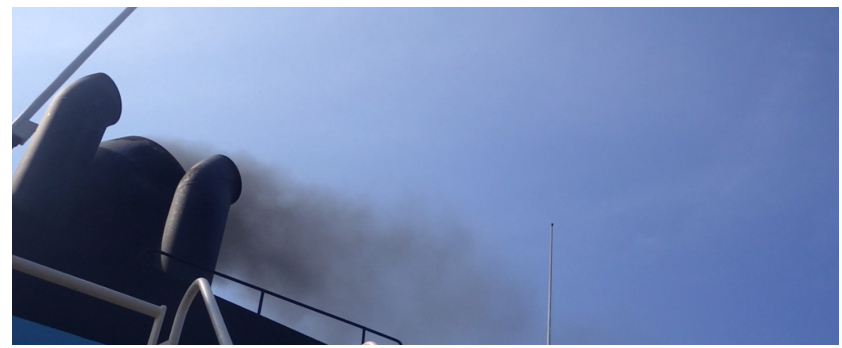

(b) $\mathrm{Y}_{L A}+\mathrm{AFF}$. The smoke level is reduced compared to the PI controller but still visible.

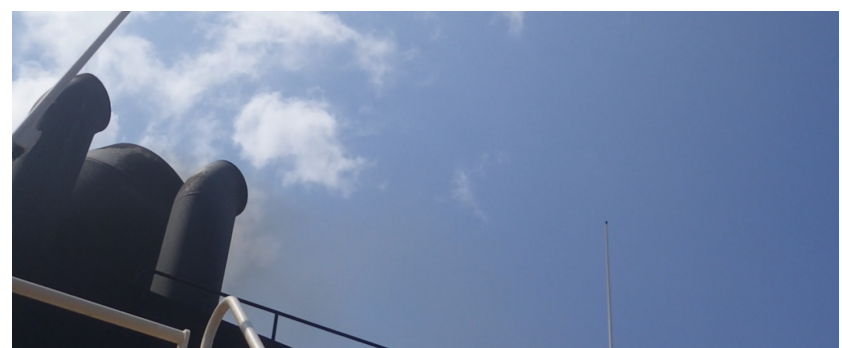

(c) $\mathrm{Y}_{L O S}+\mathrm{PI}$. Smoke formation is close to invisible.

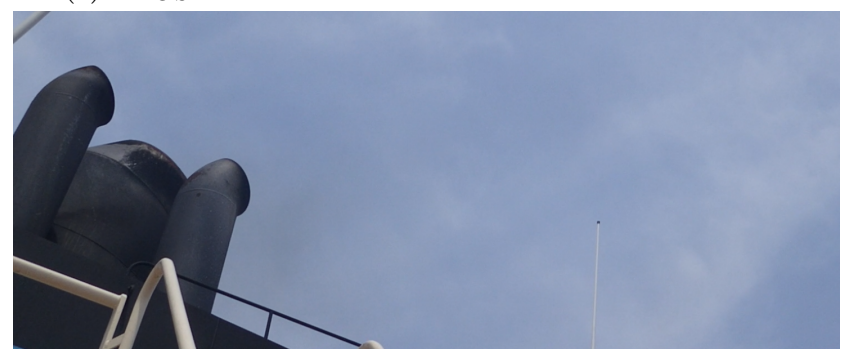

(d) $\mathrm{Y}_{L O S}+\mathrm{AFF}$. No visible smoke.

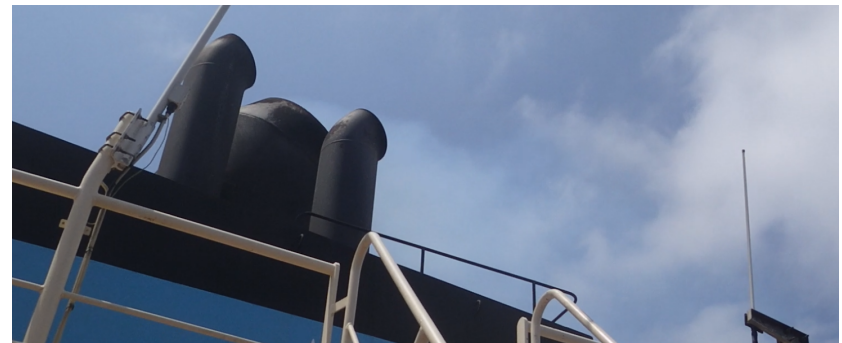

(e) $\mathrm{Y}_{L O M}+\mathrm{AFF}$. No visible smoke.

Figure 12: Exhaust smoke on a vessel with during accelerations from 35 to 50 RPM, with various combinations of fuel index limiters and EGR controllers. 
[3] T. W. P. Smith, J. P. Jalkanen, B. A. Anderson, J. J. Corbett, J. Faber, S. Hanayama, E. OKeeffe, L. Parker, S.; Johansson, L. Aldous, C. Raucci, M. Traut, S. Ettinger, D. Nelissen, D. S. Lee, S. Ng, A. Agrawal, M. Winebrake, J. J. ANDHoen, S. Chesworth, A. Pandey, Third imo ghg study 2014, Tech. rep. international maritime organization (IMO), London, UK (April 2015).

[4] M. E. P. C. International Matitime Organization, Marpol ANNEX VI and NTC 2008: With Guidelines for Implementation, International Maritime Organization (IMO), 2013.

[5] Mitsubishi Heavy Industries, Development of selective catalytic reduction for low-speed marine diesel engines, super-clean marine diesel $r \& d$ project for the imo nox tier iii regulations, Mitsubishi Heavy Industries Technical Review 47 (3) (2010) 48-52.

[6] MAN Diesel \& Turbo, Tier iii two-stroke technology, Technical Paper (2012)

URL http://marine.man.eu/two-stroke/technical-papers

[7] MAN Diesel \& Turbo, Marine engine imo tier ii and tier iii programme 2nd edition (2016).

[8] Winterthur Gas \& Diesel, Low-speed engines, (Engine Programme) (2016).

[9] Kawasaki Heavy Industries, Ltd, K-ecos, kawasaki-eco system, imo nox tier 3 compliant environmentally-friendly low emission system (July 2016).

[10] J. B. Heywood, Internal combustion engine fundamentals, McGraw-Hill, 1988

[11] K. Nielsen, M. Blanke, L. Eriksson, M. Vejlgaard-Laursen, Control-oriented model of molar scavenge oxygen fraction for exhaust recirculation in large diesel engines, Journal of Dynamic Systems, Measurement and Control - ASME 139. doi:10.1115/1.4034750.

[12] L. Guzzella, C. H. Onder, Introduction to modeling and control of internal combustion engine systems, Springer-Verlag, 2010.

[13] L. Eriksson, L. Nielsen, Modeling and control of engines and drivelines, Wiley, 2014

[14] R. Banning, M. A. Johnson, M. J. Grimble, Advanced control design for marine diesel engine propulsion systems, Journal of Dynamic Systems Measurement and Control-transactions of the Asme 119 (2) (1997) 167-174

[15] M. Blanke, Requirements of adaptive techniques for enhanced control of large diesel engines, in: Proc. IFAC Workshop on Adaptive Control and Signal Processing. Lund, Sweden, IFAC, 1986, pp. 197-202. doi:10.1016/B978-0-08-034085-2.50037-7.

[16] M. Blanke, P. B. Nielsen, The marine engine governor, in: Proceedings Second International Conference on Maritime Communications and Control, Society of Marine Engineers, London, 1990, pp. 11-20.

[17] D. E. Winterbone, S. Jai-In, The application of modern control theory to a turbocharged diesel engine powerplant, Proc. of the Institution of Mechanical Engineers, Part I: Journal of Systems and Control Engineering 205 (19) (1991) 69-83.

[18] N. Xiros, Robust Control of Diesel Ship Propulsion, Springer London, 2002.

[19] M. Blanke, J. A. Andersen, On modelling large two stroke diesel engines: New results from identification., in: Proc. IFAC World Congress, Pergamon Press, Budapest, 1984, pp. 2015-2020.

[20] E. Hendricks, Compact, comprehensive model of large turbocharged, two-stroke diesel engines., SAE Technical Paper Seriesdoi:10.4271/861190.

[21] J. B. Woodward, R. G. Latorre, Modeling of diesel engine transient behavior in marine propulsion analysis., Transactions Society of Naval Architects and Marine Engineers 92 (1985) 33-49.

[22] A. Stefanopoulou, R. Smith, Maneuverability and smoke emission constraints in marine diesel propulsion, Control Engineering Practice 8 (9) (2000) 1023-1031. doi:10.1016/S09670661(00)00024-1.

[23] M. Imperato, O. Kaario, T. Sarjovaara, M. Larmi, Split fuel injection and miller cycle in a large-bore engine, Applied Energy 162 (2016) 289-297. doi:10.1016/j.apenergy.2015.10.041.

[24] G. Theotokatos, On the cycle mean value modelling of a large two-stroke marine diesel engine, Proceedings of the Institution of Mechanical Engineers Part M: Journal of Engineering for the Maritime Environment 224 (3) (2010) 193-205.

[25] G. Theotokatos, V. Tzelepis, A computational study on the performance and emission parameters mapping of a ship propulsion system, Proceedings of the Institution of Mechanical Engineers Part M: Journal of Engineering for the Maritime Environment 229 (1) (2015) 58-76. doi:10.1177/147509021.

[26] F. Baldi, K. Andersson, G. Theotokatos, Development of a combined mean value-zero dimensional model and application for a large marine four-stroke diesel engine simulation, Applied Energy 154 (2015) 402-415. doi:10.1016/j.apenergy.2015.05.024.

[27] C. Guan, G. Theotokatos, P. Zhou, Computational investigation of a large containership propulsion engine operation at slow steaming conditions, Applied Energy 130 (2014) 370-383.

[28] C. Guan, G. Theotokatos, H. Chen, Analysis of two stroke marine diesel engine operation including turbocharger cut-out by using a zero-dimensional model, Energies 8 (6) (2015) 57385764 .

[29] S. I. Raptotasios, N. F. Sakellaridis, R. G. Papagiannakis, D. T. Hountalas, Application of a multi-zone combustion model to investigate the nox reduction potential of two-stroke marine diesel engines using egr, Applied Energy 157 (2015) 814-823. doi:10.1016/j.apenergy.2014.12.041.

[30] M. Vejlgaard-Laursen, H. R. Olesen, Controlling tier iii technologies, in: 28th CIMAC World Congress on Combustion Engine, CIMAC, 2016, paper 20160600365.

[31] J. M. Hansen, C. Zander, N. Pedersen, M. Blanke, M. VejlgaardLaursen, Modelling for control of exhaust gas recirculation on large diesel engines, IFAC-PapersOnLine, Elsevier Science 46 (33) (2013) 380-385, iFAC Proceedings Volumes. doi:10.3182/20130918-4-JP-3022.00013

[32] J. M. Hansen, M. Blanke, H. H. Niemann, M. VejlgaardLaursen, Exhaust gas recirculation control for large diesel engines - achievable performance with siso design, IFACPapersOnLine, Elsevier Science 46 (33) (2013) 346-351, iFAC Proceedings Volumes. doi:10.3182/20130918-4-JP-3022.00011.

[33] G. Alegret, X. Llamas, M. Vejlgaard-Laursen, L. Eriksson, Modeling of a large marine two-stroke diesel engine with cylinder bypass valve and egr system, IFAC-PapersOnLine 48 (16) (2015) $273-278,10$ th IFAC Conference on Manoeuvring and Control of Marine Craft, MCMC 2015 Copenhagen, 24-26 August 2015. doi:10.1016/j.ifacol.2015.10.292.

[34] K. Nielsen, M. Blanke, M. Vejlgaard-Laursen, Nonlinear adaptive control of exhaust gas recirculation for large diesel engines, IFAC-PapersOnLine 48 (16) (2015) $254 \quad-260$, 10th IFAC Conference on Manoeuvring and Control of Marine Craft, MCMC 2015 Copenhagen, 24-26 August 2015. doi:10.1016/j.ifacol.2015.10.289.

[35] K. Nielsen, M. Blanke, L. Eriksson, Adaptive observer for nonlinear parameterised hammerstein system with sensor delay - a technology for ship emissions reduction, Transactions on Control Systems TechnologyEarly access.

[36] M. J. van Nieuwstadt, I. V. Kolmanovsky, P. E. Moraal, A. Stefanopoulou, M. Jankovic, Egr-vgt control schemes: Experimental comparison for a high-speed diesel engine, IEEE Control Systems Magazine 20 (3) (2000) 63-79.

[37] J. Wahlström, L. Eriksson, L. Nielsen, Egr-vgt control and tuning for pumping work minimization and emission control, IEEE Transactions on Control Systems Technology 18 (4) (2010) 9931003. doi:10.1109/TCST.2009.2031473.

[38] J. Wahlström, L. Eriksson, Modelling diesel engines with a variable-geometry turbocharger and exhaust gas recirculation by optimization of model parameters for capturing non-linear system dynamics, Proceedings of the Institution of Mechanical Engineers, Part D, Journal of Automobile Engineering 225 (7) (2011) 960-986.

[39] J. Wahlström, L. Eriksson, Nonlinear EGR and VGT control with integral action for diesel engines, Oil \& Gas Science and Technology - Rev. IFP 66 (4) (2011) 573-586.

[40] J. Wahlström, L. Eriksson, Output selection and its implica- 
tions for mpc of egr and vgt in diesel engines, IEEE Transactions on Control Systems Technology 21 (3) (2013) 932-940. doi:10.1109/TCST.2012.2191289.

[41] H. Wang, Y. Tian, J. Bosche, A. El Hajjaji, Modeling and dynamical feedback control of a vehicle diesel engine speed and air-path, Journal of Dynamic Systems Measurement and Control-transactions of the Asme 136 (6) (2014) 061010. doi:10.1115/1.4027502.

[42] M. Huang, K. Zaseck, K. Butts, I. Kolmanovsky, Ratebased model predictive controller for diesel engine air path: Design and experimental evaluation, IEEE Transactions on Control Systems Technology 24 (6) (2016) 1-14. doi:10.1109/TCST.2016.2529503.

[43] C. Walsh, A. Bows, Size matters: Exploring the importance of vessel characteristics to inform estimates of shipping emissions, Applied Energy 98 (2012) 128-137. doi:10.1016/j.apenergy.2012.03.015.

[44] X. Llamas, Modeling and control of egr on marine two-stroke diesel engines, Linköping studies in science and technology, thesis no. 1904, Linköping University, Sweden (March 2018).

\section{Appendix A. Nomenclature}

A number of abbreviations, symbols and subscripts are used in this paper. These are indexed and briefly explained in the following three tables.

Table A.2: Abbreviations.

\begin{tabular}{l|l}
$A F F$ & Adaptive Feedforward Controller \\
$C B V$ & Cylinder Bypass Valve \\
$C O M$ & Control-Oriented Model \\
$C O V$ & Cut-Out Valve \\
$D L F$ & Dynamic Limiter Function \\
$E E D I$ & Energy Efficiency Design Index \\
$E G R$ & Exhaust Gas Recirculation \\
$I M O$ & International Maritime Organization \\
$L L O$ & Limiter Loop Oscillations \\
$M D T$ & MAN Diesel \& Turbo \\
$M V E M$ & Mean-Value Engine Model \\
$N E C A$ & NO Emission Control Area \\
$N O x$ & Nitrogen Oxides \\
$P I$ & Proportional-Integral Controller \\
$S I S O$ & Single-Input and Single-Output \\
$T C$ & Turbocharger
\end{tabular}

Table A.3: List of symbols.

Input nonlinearity

Moment of inertia

Constant

Mass

Molar mass

Mass flow

Molar flow

Molar Oxygen Fraction

Pressure

Power

Universal gas constant

Temperature

Volume

Ratio of $\mathrm{H}$ to $\mathrm{C}$ atoms in fuel

Fuel index

Limiter based on air/fuel ratio

Limiter based on oxygen/fuel ratio and model

Limiter based on oxygen/fuel ratio and sensor

Estimated parameter

Thermal efficiency

Oxygen mixing time constant

Air/fuel ratio

Oxygen/fuel ratio

Rotational speed
Table A.4: Subscripts.

\begin{tabular}{l|l||l|l}
$a$ & ambient air & $A$ & air/fuel \\
$c$ & crankshaft & $c b v$ & cylinder bypass valve \\
comp & compressor & $c o v$ & cut-out valve \\
$e b$ & EGR blower & $e n g$ & engine \\
$e r$ & exhaust receiver & $f$ & fuel \\
$F B$ & feedback & $f m$ & fuel mass flow \\
fric & friction & $i c$ & intercooler \\
ind & indicated & $L A$ & air/fuel limiter \\
LO & oxygen/fuel limiter & $M C R$ & maximum continuous rating \\
$O$ & oxygen & $O_{2}$ & oxygen molecules \\
prop & propeller & $s r$ & scavenge receiver \\
$S P$ & set point & trap & trapped \\
tc & turbocharger & turb & turbine
\end{tabular}

